\title{
Intra-organizational Selection: Phenomenon and Its Behavioural and Cultural Determining Factors
}

\author{
Ewa Stańczyk-Hugiet ${ }^{1}$, Katarzyna Piórkowska ${ }^{1} \&$ Sylwia Stańczyk $^{1}$ \\ ${ }^{1}$ Wroclaw University of Economics, Poland \\ Correspondence: Ewa Stańczyk-Hugiet, Wroclaw University of Economics, Department of Strategy and Management \\ Methods, 53-345 Wroclaw, Poland, Komandorska Street 118/120, Poland.
}

Received: August 2, 2015

doi:10.5430/jms.v6n4p1
Accepted: August 24, $2015 \quad$ Online Published: September 16, 2015

URL: http://dx.doi.org/10.5430/jms.v6n4p1

This research was supported by a grant financed by the National Science Center; decision number DEC-2013/11/B/HS4/00647.

\begin{abstract}
The aim of this paper is to provide a conceptual scheme concerning intra-organizational determinants of primary selection. The authors present the evolutionary theory as appropriate background for the research approach. Consequently, this paper, stressing the importance of selection mechanism, reviews evolutionary achievements. There is also presented the review of routine approaches, as routines constitute the object of selection. Then, authors provide the proposition based on the theoretical review concerning the role of managerial and cultural selectors in organizational evolution, especially in the process of routines selection. This paper contributes to the body of research on the routines, evolutionary theory, behavioural and cultural stream of research. Thus, it explores the evolutionary approach from the perspective of primary selection and its determinants. The authors provide an extension to the selection logic as for behavioural and cultural determinants of primary selection. Due to practitioners, they are recommended to consider personal behavioural characteristics and cultural ones as either hindrance or enablers of changes.
\end{abstract}

Keywords: evolutionary change, primary selection, behaviour/attitude, organizational culture

\section{Introduction}

Researching changes becomes still a challenge. A number of studies on changes evidence that the results in that field are not exhaustive. In many papers and articles the further research directions have been stressed. Pettigrew (1987) has formulated some hints for scholars. He regards that proper theory of changes ought to simultaneously explain stabilizing forces and changing ones, acknowledge and encompass the considerations of exogenous and endogenous sources of changes, interrelate phenomena at the micro- and macro level of an analysis, take into consideration the compatibility of problems due to the degree and direction of changes. Additionally, researchers ought to be conscious of precariousness in terms of understanding and formulating theory of changes and to assume that their work constitutes the interpretation and consideration of a contextual idea, the processes and contents of a change as well as of the ability to regulate relationships amongst these three issues.

According to Van de Ven (1987), a strong theory of changes ought to explain: how a structure and individual intentional actions are interrelated at the micro- and macro level of an analysis, how a change is created by both internal structure's functioning and external individual intentional actions as well as stability and instability, how time could be considered as a clue historical measure.

It is propounded that evolutionary ontology and epistemology, which is not excessively developed in the current studies, give an opportunity to enlighten changes concept in a relatively complex way. It is possible since the evolutionary approach enables to explain stabilizing forces and changing forces (e.g. routines), acknowledge and include the considerations of exogenous and endogenous sources of changes (e.g. access to resources), connect phenomena at the micro- and macro level of an analysis (i.e. co-evolution concept), take into consideration the compatibility of problems due to the degree and direction of changes.

In accordance with the Nelson and Winter's work (1982), the evolutionary theory in the field of management science 
is embedded in the economic managerial decision-making concepts, however, they indeed concern economics, industry, and economy. Similarly, Aldrich's work (1999), although is helpful in determining what an organization is, how an organization changes, which behaviour are incorporated into an organization, its content is addressed merely indirectly to managers. Economic and social phenomena are so strongly inspired by the evolutionary approach that the endeavours of incorporating it into management science are still made. For instance, Durand (2006) attempted to associate an evolutionary theory with a resource-based view. An evolutionary approach might raise concerns amongst the scholars in the field of management science since it constricts the relevance of managerial roles (Murmann, Aldrich, Levinthal \& Winter, 2003) at least regarding a classic approach. On the other hand, Lovas and Ghoshal (2000) emphasize an active role of managers in a model of directed evolution. According to the arguments presented by Salvato $(2003 ; 2009)$, it is assumed that managers sufficiently understand the process of organizational growth and they can manage to intentionally create this growth in accordance with a repeatable set of recombined patterns until developing organizational chances.

An evolutionary paradigm is essentially associated with Darwin's work and the theory of natural selection. Although the Darwin's theory is cognitively attractive, it is extensively criticized at the same time. The strategic management issues are primarily related to Mintzberg's work envisioning that a strategy evolves and is determined by exogenous changes. Neverthless, Mintzberg does not satisfactorily explain the mechanisms of evolution. In turn, Lovas and Goshal's concept (2000) brings added value through explaining the strategy evolution in the categories of directed evolution. The authors have envisaged that in the process of evolution two selection mechanisms occur: strategic initiatives as well as human and social capital. The strategic initiatives reflect organization's intention and resources are developed for creating value (i.e. human and social capital) by determining the ways of realizing the intention. Nonetheless, inside an organization, the coevolution, understood as the mechanism of spontaneous and frequently not controlled self-organization, of human capital, social capital, and strategic initiatives acquires growing importance. There are other proposals of incorporating the evolution theory into management science: i.e. Durand, 2006; Nelson \& Winter, 1982; Baum \& Singh, 1994, Volberda \& Lewin, 2003. The influential work of Nelson and Winter has been the most intensively used in management science recently, apart from the Schumpeter or Mintzberg, Linblom \& Quinn's work explaining the issues of strategy dynamics, an emergent strategy or logical incrementalism. Those approaches reflect the relevance of exogenous changes and there is empirical justification, although it frequently provides little contribution, that organizational solutions are solely created by exogenous changes and intra-organizational order is employed by exogenous grassroots alteration. A salient hypothesis, clarifying the strategic management concerns, subsumes that in practice managers deliberates, however, a market makes decisions.

An evolutionary research perspective is conformed to explain the mechanisms of operating an organization in complex environment. The evolutionary approach is all the more significant, as there are very few literature studies about evolutionism incorporation for resolving contemporary dilemma in management, including strategic one. Evolutionary mechanisms in management are naturally connected with an evolutionary cycle that emphasizes variation, selection, and retention (Campbell, 1996).

A dynamic evolutionary process is sequentially described by Andersen (1994). He generalizes processes of evolution sixfold. First, the organization's characteristics determine organizational actions related to the relationships with environment (input and output). Second, the confrontation with exogenous variables determines the effectiveness of an organization. Third, the effectiveness of an organization influences the possibilities of expanding actions and makes them competitive towards the other organizations. Fourth, the process creates a dynamic change and the same routines explored in the new conditions generate different effects. Fifth, the mutation of decisional roles occurs. After each iteration, the organization acquires new process routines that enable to improve the organization's features. It also provides investment routines for the next iteration. Finally, sixth, the processes of selection and variation make the organization evolves.

The mechanisms of variation and selection are important to understand the complete evolutionary research perspective. In the stream of research having been explored in management science, the logic of variation is dominant (Nelson, 1995, Zollo \& Winter, 2002) (i.e. from the perspective of management systems, organizational solutions, routines, etc.). As a result of variation, retention, resistance, and replication occur (Metcalfe, 2006). The processes of variation and the processes of selection are interrelated each other since the selection cannot exist without variation. Consequently, emerging coherent units selected constitutes the effect of variation.

The evolutionary logic, in principle, involves selection rationale. The selection phenomenon is associated with the idea that the "best" elements are selected - referring thereby to specific criteria such as fitness and efficiency. In general, the evolutionary approach is concentrated on selection made by environment that is called exogenous 
(external) selection, however, in some cases, it is focused on selection inside the organization (dubbed endogenous, internal selection). That internal selection is hardly ever explored in studies. Nevertheless, an evolutionary metaphor is used in many sciences since it is equated with progress and cognitive inspirations.

There are many studies on the selection process, however, the research results obtained do not explain extensively the logic of selection inside the organization and they rather refer to general evolutionary rationale while the selection logic in the organization is solely alluded. Consequently, exploring selection mechanism inside the organization might be useful in complementing management science in terms of exploiting evolutionary rationality.

From this perspective, this paper complements management science by evolutionary rationality. The current research on explaining the complex process of selection is far away to be exhaustive. That is the reason why a research gap has been identified in this field. Consequently, the purpose of the paper is to clarify, develop and complement management science based on the evolutionary approach in the field of management theory. To realize the purpose, the studies in the field of evolutionary change, principally in terms of the selection mechanisms, processes, and determinants have been examined. Consequently, a theoretical framework and propositions explaining determinants of organizational survival have been presented incorporating the concept of primary selection and routines. In the final section, the implications of this study and the future research directions have been discussed.

\section{Selection Process - Framework}

The evolutionary logic, in principle, involves selection rationale. According to Teece (2010), adaptation is significant as the most fitted units are selected. Environment selects such units from the whole population. Selection is the mechanism which evolution uses for adaptation purposes. The selection mechanism allows selecting the units that are the most fitted for current contextual conditions. In the beginning, the selection process was recognized linearly. Next, it has become more complex and multilevel, especially in social sciences, as the impact of not stable behaviour on tendencies and disposals for actions is not obvious. Hence, not only external selection, but also internal one appears to be also salient. The model of Darwin (variation, inheritance, selection) has been implemented in management science as variation, selection, and retention. The selection performs in organizations at multiple levels and continuously. In turn, imitation and innovation intermingle and create the mainstay for entrepreneurship (Eliason, 2008; Hanusch, 2008). Consequently, so as to understand changes in organizations it is necessary to pay attention to selection forces active at multi levels of the analysis.

The selection process is complex and is perceived from many perspectives. The logic of selection is characteristic for the evolutionary approach. The selection is related to the fitness degree ensuring the vitality of an organization. It means that particular behaviour decreasing the fitness degree of a unit in a system simultaneously increases the fitness degree of the whole organization. The selection exploited at many levels enables to more comprehensively understand its logic, mechanisms, and determinants. Sober and Wilson (1998) suggests using the scheme of multilevel selection since the fitness at the higher level is possible although some activities reduce fitness degree at the lower level. As an instance, individuals in the organization (similarly: organizations in the sector) make actions reducing their fitness degree in terms of operating in a long-term, increasing revenues or effectiveness, insofar as such actions result in reducing the degree of fitness to the system at the higher level.

Exploring the selection issues, it is necessary to examine the two qualitatively different processes of selection: selection of and selection for organizations what constitutes another classification. The selection of organizations is made by environment, while the selection for organizations is made by managers endeavouring to ensure the survival of the organization. The selection for organizations is concentrated on the selection mechanisms such as: value appropriation, information asymmetry, innovation, allocation, and the access to resources. In that case, the routines constitute the units of selection, especially connected with inter-organizational mechanisms what is emphasized in a resource-based view as well. On the other hand, environment selects by means of selectors such as: resources rareness, norms, routines, or structural inertia (Levin \& Volberda, 1999).

The selection mechanism performing inside the organization has been merely highlighted in the literature. Taking into account the research logic in the field of population ecology, it is only partially possible to understand the selection mechanism since the process of selection occurs at multiple levels. Additionally, the population ecology gives dignity to the external selection that explains how environment selects organizations that will survive or die (Hannam \& Freeman, 1992). In this approach, environment acts as the agent of evolution as organizations only react to changes in the environment - frequently in the way that does not enable them to adapt. Organizations encounter external events, i.e. innovations, crucial technologies (Christensen, 1997) that influence the selection mechanism. Moreover, they are embedded in the process of creating 'new' organizations and the result is that organizations existing on the market with old ideas, products, technologies, etc. become the preyers of selection made by 
environment (Nelson \& Winter, 1982; Wirtz, Mathieu \& Schilke, 2007). Nonetheless, that mechanism has not been explained enough. Consequently, the supporters of external selection pessimistically perceive the possibilities of adapting, especially in high-velocity environment (Eisenhardt, 1989).

Those limitations lead to the ascertainment that it is justified to explore the mechanisms of primary and secondary selection, positive and negative selection as well as weak and strong one. As a result, the processes of primary (performing in the organization) and secondary selection (environment selects) have been conceptualized.The second important issue is that the selection might be either positive or negative. The negative selection results in eliminating initiatives in the organization and even the organization itself. The positive selection leads to replicate patterns and forms inside the organization and then in environment. The next selection typology is associated with the strength of internal selection mechanisms. Weak mechanisms of internal selection result in the reactivity of the organization. The weak mechanisms of internal selection supported by the force of external selection reflect the simple fit and consequently the most fitted units occur. Strong internal selectors are more creative. The creativity accompanied by weak external selectors enables to influence or even create external environment, yet accompanied by strong external selectors generates the co-evolution that favours the vitality of the organization.

Primary selection is the process in which grassroots initiatives and routines competing for resources and the managers' attention arise. Managers, as the agents of evolution, make selection attempting to predict the future directions of technology development, competition, and market demand. In view of bounded rationality, their decisions might be wrong. Considering that context, evolution encompasses the processes of variation, selection, and retention that enable the organization to transform. Consequently, the organization is an idiosyncratic portfolio (i.e. of products, systems, routines, etc.) formed in the process of selection. Hence, primary selection emphasizes a meaningful role of organization's autonomy in creating the possibilities of surviving. Thus, the environmental changes do not much influence organization's survival. This optimistic approach is concentrated on protecting a core activity and reliability enabling to survive. The primary selection, explained in this way, results in internal adaptation, which enables the organization to survive in mature environment. According to Santos and Garcia (2007), not only are objective conditions resulting from environment pressure important, but also determinants connected with the possibility of managerial interpretation since managing adaptation requires both the emergence from a dynamic context and the ability to project the organizational renewal process.

In conclusion with all considerations, the tension between primary and secondary mechanisms of selection arises since the processes of primary selection and secondary one are interrelated each other. The learning processes evidence that phenomenon. Cumulative and adaptive learning emerge not only from the processes of primary selection, but also from the secondary selection mechanisms. These processes co-evolve, however, secondary selection more influences the survival of the organization than internal one (Henderson \& Stern, 2004). In turn, adaptation as selection intention does not mean solely the adjustment to environment, accordingly to Siggelkow (2001) who distinguishes internal and external adjustment.

The phenomenon of the organization evolving does not contradict the potential for managers to affect the organization and the legitimacy of managing changes. Nevertheless, it differs from traditionally managing an organizational change as it limits managerial omnipotence and stresses the role of circumstances pressure. Santos and Garcia (2007) highlight the role of managers (agents). Howard-Grenville (2005) explains why flexible routines are possible to be kept after some time and he also endevaours to elucidate the agent's impact on lodging routines. The outines are recognized traditionally as the source of inertia, calmness, stability. The routines' change is said to be a result of the need to adapt. Additionally, it is thought that routines change every day (Feldman, 2000; Pentland \& Feldman, 2003) and intentional changes do not affect the changes of routines. The way in which routines reveal in actions is essential in the process of selection.

The salient issue in terms of exploring selection processes is to answer the following question: what is a subject of selection? According to Nelson and Winter (1982), the subject of selection constitute routines and competencies whose diffusion determines selection processes and consequently the survival or death of the organization. Due to Dawkins (1976), routines and competencies are endowed with a selfish gene causing that routines and competencies do not care for an organization and an organization lives until routines are being promoted (retention or replication). Dawkins introduced the notion 'mem', which means an autonomic unit that is imitated under replication and mutation. On the other hand, assuming the existence of epistasis, routines cannot live in isolation. Without regard to the epistemological approach, the selection is connected with results achieved and its subject constitutes routines and competencies (regardless whether we accept the thesis about routines' isolation or we regard that they function in a context). 
Addmitedly, the routines are enucleated in many ways. Hence, the answers for the following key questions ought to be found: What kinds of behavioural tendencies are qualified as routines, and what kinds are not? Why routines are qualified as replicators, yet rules and structures are not (Hodgson \& Knudsen, 2004)? The most challenging concern is that any indisputable conceptualization of routines in terms of their content has not been established so far. For instance, Becker, Salvatore \& Zirpoli (2005) have placed authors of the routines concept into three different groups. The first one defines routines as behavioural patterns. The second group defines them as rules - standard operating procedures - in the same sense that the first group consents that they are recurring patterns. The last group defends the idea that routines are collective willingness to adopt acquired or previously used behaviour according to the certain stimuli or context. The term 'routines' ought to be understood as 'recurrent patterns of interaction' (Becker, 2002). Hodgson \& Knudsen (2004) state that routines constitute 'organizational meta-habits' that cannot be reduced to the individual level. When defined as behavioural tendencies, routines become non-observable, what considerably complicates empirical analysis and testing hypotheses. The routines are generative systems that produce repetitive, recognizable patterns of interdependent actions carried out by multiple participants (Feldman \& Pentland 2003; Pentland \& Feldman 2005).

Conceptualizing routines phenomenon, an organization is exploited as a unique idiosyncratic assembly of routines. Consequently, it means that routines either survive or die dependently whether an organization survives or dies. Thus, the selection of an organization is unambiguous with the selection of routines. Therefore, the following proposition has been formulated:

Proposition 1: The organizational routines determine the survival of an organization recognized as positive selection made by environment.

\section{Internal Determinants of Primary Selection}

The selection is the primary mechanism of evolutionary changes. It seems it performs invariably and continuously asesses the fitness degree. The selection requires being specified regarding its reasons and forms. Neither a strategy nor strategic management can effectively create solutions and influence an action without the knowledge how organizational evolution operates at each level (intra and supra organization).

Consequently, explaining how primary selection, where the routines are perceived as the selection object, is intra-organizationally determined seems to acquire great importance, especially from practical point of view.

We state that internal factors are compelling in organizational evolution that is limited by organizational inertia, while learning opens the space for actions. On one hand, the top managers perception might catalyse or obstruct the initiatives of middle managers; on the other hand, organizational attention could structure or draw aside the evolution process what might result in various (diverged from predicted) organizational effects.

Consequently, the presented conceptual framework concerns the intra-organizational determinants of evolution. The attempts of explaining that direction seem to be relatively complex in evolutionary theory. Hence, it has been assumed that a general premise of evolution has sense and gives the direction of analysing complex processes as well as that the evolution theory rationale will enable to recognize and explain such complex processes.

The proposed conceptualization is concentrated merely on the determinants of primary selection in the area of activities undertaken inside the organization that result in positive or negative external organizational selection over the long term. The basic assumption that has allowed us to develop the proposed conceptual scheme is: every intra-organizational change is the resultant of two effects: intentions of managers and cultural environment pressure. Organizational routines seem to be the primary selection unit (object of the analysis). Consequently, endogenous changes determined by intra-organizational factors are driving forces of a change and experience.

It leads to explain whether and how behavioural and cultural mechanisms are driving forces of organizational evolution. Such a perspective is subsumed to be supportive in explaining: the process of adjusting an organization to changes (adaptiveness), the originality of organizational-managerial and strategic solutions, and the organization uniqueness resulting in enhancing competitiveness. Accordingly, we have formulated the following proposition:

Proposition 2: The primary selection of routines in an organization is a result of the interdependent impact of behavioural and cultural selectors.

The determinants of primary selection are aggregated into two coherent sets. The behavioural intra factors, so-called managerial selectors are the first one. They refer to attitudes and/or behaviour as well as psychological features because routines have reflective character and allow managers to enhance the level of trust to employees' behaviour. The important issue in here is to motivate to routines' changes. The managerial intentions also matter as determined 
by attitudes and/or behaviour as well as psychological characteristics reveal in endeavours to create artefacts.

The second group of determinants consists of cultural intra factors, so-called cultural selectors. The assumption of existing cultural selectors determining the primary selection mechanisms is justified since artefacts constitute the demonstration of organizational routines (Pentland \& Feldman, 2005).

\section{Discussion}

\subsection{Routine Selection - Behavioural Perspective}

Behavioural characteristics of managers determine the ability to identify and manage primary selectors. One of the features of a manager determining the selectors character might be organizational adjustment of the manager reflecting in inter alia such correlates like: particular attitudes and/or behaviour (including behavioural intention), especially social attitudes (Hall \& Lindzey, 1957; Makin, Cooper \& Cox, 1997; Robbins \& Coulter, 2005), and particular psychological traits (especially temperament, personality, character, resistance to change/managing occupational stress).

Considering social attitudes, it seems that the following social attitudes of managers potentially directly or indirectly influence the character of selection processes: conformity versus non/anti-conformity, individualism (even opportunism) versus collectivism, proactivity versus reactivity (indifferentism) and social loafing connected with the processes of social facilitation and affecting the effectiveness of the process of creating novel routines and retaining sufficient current ones (Hobfoll, 1998).

The research on conformity concerns the analysis of the pressure on an individual so as to adjust the individual to the expectations of leaders, groups, society, or organizations, (research of S.E. Asch \& R.K. Merton). Managerial conformist and nonconformist behaviour (attitudes and/or behaviour) could determine the character of activities making them more or less oriented to adaptive processes. With reference to an individual social attitude, opportunism is perceived rather negatively. Nevertheless, taking organizational routines and evolutionary rationale into consideration, opportunistic behaviour is a common phenomenon recognized even as the rational one from the perspective of effective criteria assessing selection mechanisms. The instance of opportunistic behaviour might be orientation towards strong adaptive processes on one hand, and behaviour focused on avoiding excessive risk, on the other hand.

It could be assumed that 'proactivity' is the contrary phenomenon to 'reactivity' ('indifferentism'). Adapting the nomenclature to describe organizational routines perspective, proactive activities are mostly focused on innovations, entrepreneurship, seeking occasions, or aggressive initiatives - those categories are recognized in the context of emerging routines. In contrary, the hallmark of indifferent managerial behaviour is inertia.

Social facilitation is a process revealing that the presence of other people increases the organism mobilization as a result of strong physiological excitement (Zajonc, 1965; Hamer 2005). Allport called this phenomenon social increment. The research on social facilitation evidences that the presence of other people enhances effectiveness of actions if an individual works on easy, well learnt tasks, however, the presence of other people hampers the effectiveness if the individual is engaged in realizing difficult tasks that are not mastered enough (Zimbardo, 2005). This process dubbed social loafing or a Ringelmann effect reflects that efforts in realizing tasks are lower-intensive in the case when an individual acts with other people than in the case when an individual does not feel the responsibility for efforts' effects, namely when inputs of particular individuals due to a final effect is difficult to be recognized. Summarizing those considerations, managers' personality tendencies for social loafing might destructively influence the effectiveness of primary selection processes in the organization.

The process of identifying and managing selectors might be also determined by personality correlates like personality (Cloninger, 1994), temperament, character (Hall \& Lindzey, 1957), resistance to change/managing occupational stress. According to Kenrick, Neuberg \& Cialdini (2005) and Pervin (1989), human behaviour is determined to a similar extent by motivation and personality. Personality is expressed stronger when there is freedom of expressing it what means a high level of work autonomy and/or that external requirements and norms are not important (Makin, Cooper \& Cox, 1997).

The influence of temperament, as an energetic characteristic of behaviour, on the manager's abilities to realize the processes of primary selection is likely to have a prominent role. The primary selection process requires the tendency to take a risk what implies the necessity of resistance to organizational stress and working out an effective style of coping with stress (Robbins, 2015). Concluding, the next proposition has been formulated as follows:

Proposition 3: Managerial selectors such as managerial attitudes and/or behaviour as well as managerial 
psychological traits determine the selection of particular organizational routines.

\subsection{Routine Selection - Cultural Perspective}

As for the research on organizational culture, the research gap due to evolutionary rationality has been also identified. The interest in organizational culture occurred in management at least in the time of developing the Human Relations stream emphasizing the importance of cooperation amongst individuals so as to efficiently operate in an organization. In the 1970s, organizational culture became the concept in management and organization science (Pettigrew, 1979) and in the 1980s it acquired more scholars' attention (e.g. Deal \& Kennedy, 1982; Peters \& Waterman, 1982). The phenomenon of organizational culture enriched management science with a new perspective. The basic research results on organizational culture impact on management science include, amongst others: (a) the attempts of creating theoretical underpinnings for a cultural stream in management, (b) qualitative analyses of organizational culture definitions (e.g. Smircich, 1983/1987; Allaire \& Firsirotu, 1984; Czarniawska-Joerges, 1991 and further; Schultz, 1995; Hatch, 2002), (c) proper research methodology including operationalization (Hofstede, 1980), (d) pointing possible strategies of cultural changes, their consequences, sources, courses, features favouring changes (e.g. Bate, 1984/1990; Davis, 1984; Quinn \& McGrath, 1985; Gagliardi, 1986; Kilmann, Saxton \& Serpa, 1986; Kotter \& Heskett, 1992; Cuhna \& Cooper, 2002; Sheffi, 2005), and (e) studies including single cases describing the model of cultural elements (e.g. Peters \& Waterman, 1982) or model-based considerations of culture types (e.g. Harrison, 1972; Handy, 1976; Deal \& Kennedy, 1982; Goffee \& Jones, 1997; Cameron \& Quinn, 2003). Additionally, the interest in organizational culture resulted in recognizing various cultural patterns, norms and organizational values determined by the context of social culture (e.g. Hofstede, 1980; Hampden-Turner \& Trompenaars, 1993; Gesteland, 1996, House, Hanges, Javidan, Dorman \& Gupta, 2004). Moreover, it has eventuated in many publications constituting either the exemplification of both deep qualitative studies on national cultures or the identification of cultural diversities dimensions.

A cultural problem has become important in the times of dynamic growth of organizations on foreign markets, yet the research conducted in this field evidences some conclusions illustrating managers' reluctance and misunderstanding over the relevenace of cultural concerns. According to small and medium sized enterprises, some conclusions could be quoted: the most of companies neglect social activities; many organizations despite favourable conditions for creating organizational culture do not comprehensively use available tools; in many companies the common phenomena are: poor level of knowledge about organizational culture usability in practice; hindered access to organizational knowledge; the conviction that the phenomenon of organizational culture affects only big enterprises.

Although cultural aspects are fashionable in practice, they raise discouragement due to their indeterministic soft character, immeasurable effects and long-term results of intentionally creating organizational culture. It is noticeable that current research in this field is concentrated on the essence of cultural phenomenon or on pointing its importance as a strategic resource. Consequently, the research problems have been regarded as the exhaustive ones and scholars have not provided the complex solutions. Nevertheless, the studies on organizational culture ought not to be limited only to endeavours to know and describe this phenomenon.

A basic methodological problem in the context of organizational culture deals with selecting a research subject in this field. This issue is resolved with the models of organizational culture recognizing its elements. Organizational culture includes both external forms in which it is revealed (symbols/artefacts) and more or less deeply hidden elements. The structure of culture is multidimensional - encompasses not only basic elements, but also derivative, secondary ones that obviously are not less salient than basic constituents are. One of the attempts of systematizing organizational culture elements and explaining mutual relationships amongst them is a clinical model by E. Schein. According to the model, culture comprises of characteristic parts called the culture levels that have been distinguished in terms of durability and perceptibility. Schein has identified three levels of culture: artefacts (visible), espoused beliefs and values (may appear through surveys) and basic underlying assumptions (unconscious and taken for granted beliefs and values: these are not visible) (Schein, 1985).

The most visual culture level is the system of symbols constituting an artificial figment of a given culture called artefacts. Artefacts reflect visual, tangible, and audible remains of behaviour embedded in cultural norms, values, and assumptions (Gagliardi 1990). The artefacts include physical subjects created by culture members, verbal symptoms visible in written and oral language, rituals, ceremonies, and other patterns of behaviour. Addmitedly, those issues are significant in examining routines since artefacts are the peculiar demonstration of organizational routines (Feldmann $\&$ Pentland, 2005). As a result, the fourth proposition has been stated:

Proposition 4: Cultural selectors (artefacts) determine the selection of particular organizational routines. 
Although culture artefacts are external, they ascertain the internal organizational existence. Organizational cultures are implicite phenomena consisted of orientating patterns that are incorporated by the organization's members, while the process of reconstructing 'orientation world' begins with visual culture elements (Steinmann \& Schreyögg, 2005). Culture is a multi-faceted term. It refers, but is not limited, to belief systems, behavioural repertoires, causal mappings, status hierarchies, trust relationships, and social capital. It is all of those things and more. Culture determines how we interpret and proceed information, how we act, and how we expect others to act (Bednar \& Page, 2006). Consequently, so as to understand culture it is necessary to begin considerations with phenomena recognizable externally. Indeed, they determine the selection of routines.

\section{Conclusion}

This paper contributes to the body of research on the routines, evolutionary theory, behavioural and cultural stream of research. In this study, the authors have explored the evolutionary approach from the new perspective. Firms are viewed as an idiosyncratic reportoire of routines. The authors have extended recognizing the selection mechanism to behavioural and cultural determinants of primary selection in terms of the research gap that has been identified, especially in the field of the managers' impact on selectors.

The presented framework contributes to complement the research field incorporating the evolutionary logic to the processes inside the organization. According to the state of the art presented, the justification of the proposed concept is based on the endeavours to significantly enhance knowledge about behavioural and cultural mechanisms of primary selection at the ontological, epistemological, and axiological level. Additionally, it ought to be emphasized that behavioural and cultural mechanisms of primary selection embedded in the evolutionary logic has not been recognized yet what proves the validity of the proposed research. Moreover, the paper contributes to enrich an evolutionary research perspective in the field of management science.

The paper provides a number of both empirical and theoretical implications for further research. Empirical research requires encompassing behavioural and cultural mechanisms' influence on routines selection that in turn determines the survival of the organization. Consequently, managers are advised to understand the limitations and enablers of the behavioural and cultural context in terms of business survival, including the influence of artefacts. Whereas researchers have long examined organizational evolution, the literature predominantly focuses on the role of external selection. However, this prevailing view falls short of explaining how firms adapt successfully to long-term and complex issues and what internal factors influence such adaptation. There may be an evolutionary explanation for the multiple approaches to the selection process. Our findings support the view that the conceptualization of behavioural and cultural characteristics of primary selection is theoretically important as it explains the role of internal mechanisms of organizational evolution. Nonetheless, our conclusions and propositions, as every study, must be considered in the light of the conceptualization limitations. Therefore, one aspect concerns the methodology of examining organizational routines. It is illustrated in the most of studies that the scholars still seek proper methods and they are not convinced of the legitimacy of a particular methodological path. The empirical research on routines makes serious difficulties. First, routines are dispersed in the organizational time and space and are embedded in organizational relationships. Second, the research on routines is conducted differentially, namely from not-formalized approaches to intuitional ones (Nelson 2009), via qualitative research supported by Feldman's meta-theory (Feldman, 2000; Pentland, Feldman, 2005), ethnographic studies (Howard-Grenville, 2005), log event research and its representation in the form of graph search (Van der Aalst, Reuers, Song, 2005) to induction (Pentland, Haerem, Hillison, 2009) or the analyses of sequences and their rules (Salvato, 2009). According to the theoretical implications, the presented framework has stressed the necessity of much deeply discussing the managerial characteristics related to particular routine types and the organizational culture roles in these aspects. It is also required to better understand the business internal dynamics in terms of the processes that companies use to transform themselves from the passive objects of external selection into the active agents of organizational evolution. Moreover, it is essential to deeper understand the relative role of managerial behaviour and organizational culture in organizational evolution.

Consequently, as all studies, our analysis has limitations, yet they provide the opportunities for further research. The future research may therefore explore phenomena regarding long-term survival and/or intraorganizational characteristics, as well as the routines indicators that allow to objectively assessing the long-term adaptation activities. Our study also substantiates a more complex view of organizational antecedents' impact on organizational growth. The further research is planned to explain how primary selection (in which the routines are the selection object) determined by intra-organizational characteristics implies the profile of organizational fit (fitness), all the more so the findings of this paper provide the foundation for future investigation and research. 
The paper contributes also to the practice field. The practitioners should consider personal behavioural characteristics as limits or enablers of changes as well as organizational culture, especially in the area of artefacts, should be in the practitioners' spotlight since it clearly reflects the organizational routines. Moreover, the behavioural and cultural mechanisms might determine the necessity to change routines or not to change.

For these reasons, the routines acquire greater importance from a strategic perspective. Hence, the managerial decisions should be examined, explored, and explained not only in terms of their own capabilities and limitations, but also in the context of more broadly-understood intraorganizational determinants.

\section{References}

Aldrich, H. (1999). Organizations evolving. London: Sage.

Andersen, E. (1994). Evolutionary Economics: Post-Schumpeterian Contributions. London: Pinter Publishers.

Baum, J. A. C., \& Singh, J. V. (1993). Organizational niches and the dynamics of organizational founding. Organization Science, 5(4), 483-501. http://dx.doi.org/10.1287/orsc.5.4.483

Becker, M. C. (2002). The concept of routines twenty years after Nelson and Winter (1982). A review of the literature. DRUID Working Paper no 03-06; Retrieved December 20, 2014, from http://www3.druid.dk/wp/20030006.pdf

Becker, M. C., Salvatore, P., \& Zirpoli, F. (2005). The impact of virtual simulation tools on problem-solving and new product development organization. Research Policy, 1305-1321.http://dx.doi.org/10.1016/j.respol.2005.03

Bednar, J., \& Page, S. E. (2006). Culture, Institutional Performance, and Path Dependence. Institute of Governmental Studies Paper. Retrieved from https://escholarship.org/uc/item/1bq6d126

Campbell, D. T. (1996). Variation and selective retention in sociocultural evolution. General Systems, 14, 69-85.

Christensen, C. M. (1997). The Innovator's Dilemma: When New Technologies Cause Great Firms to Fail. Harvard Business School Press.

Cloninger, C. R. (1994). Temperament and Personality. Current Opinion in Neurobiology, 4(2), 266-273. http://dx.doi.org/10.1016/0959-4388(94)90083-3

Dawkins, R. (1976). The Selfish Gene. Oxford: Oxford University Press.

Durand, R. (2006). Organizational Evolution and Strategic Management. London: Sage.

Eisenhardt, K. M. (1989). Making fast strategic decisions in high velocity environments, Academy of Management Journal, 32(3), 543-576. http://dx.doi.org/0.2307/256434

Eliason, G. (2008). Applications of Schumpeter's Ideas. In H. Hanusch (Ed.), Evolutionary Economics (pp. 151-198). Cambridge: Cambridge University Press.

Feldman, M. S. (2000). Organizational routines as a source of continuous change. Organization Science, 11(6), 611-629. http://dx.doi.org/10.1287/orsc.11.6.611.12529

Feldman, M. S., \& Pentland, B. T. (2003). Reconceptualizing organizational routines as a source of flexibility and change. Administrative Science Quarterly, 48, 94-118. http://dx.doi.org/10.2307/3556620

Gagliardi, P. (1990). Artifacts as Pathways and Remains of Organizational Life. In P.Gagliardi (Ed.), Symbols and Artifacts: Views of the Corporate Landscape. Berlin: Walter de Gruyter.

Hall, C. S., \& Lindzey, G. (1957). Theories of personality. Hoboken, NJ, US: John Wiley \& Sons Inc. http://dx.doi.org/10.1037/10910-000

Hamer, H. (2005). Social Psychology. Warsaw, Poland: Difin.

Hannan, M. T., \& Carroll, G. (1992). Dynamics of Organizational Populations. Nowy Jork: Oxford University Press.

Hanush, H. (2008). Evolutionary Economics: Applications of Schumpeter's Ideas. New York: Cambridge University Press.

Henderson, A. D., \& Stern, I. (2004). Selection-based learning: The coevolution of internal and external selection in high-velocity environments. Administrative Science Quarterly, 49, 39-75. http://dx.doi.org/10.2307/4131455

Hobfoll, S. (1998). There's more than rugged individualism in coping. Anxiety, Stress and Coping, 11, 137-165.

Hodgson, G. M., \& Knudsen, T. (2004). The firm as an interactor: Firms as vehicles for habits and routines. Journal 
of Evolutionary Economics, 14(3), 281-307. http://dx.doi.org/10.1007/s00191-004-0192-1

Hofstede, G. H., Hofstede, G. J., \& Minkov, M. (2010). Cultures and Organizations: Software of the Mind. New York: McGraw-Hill.

Howard-Grenville, J. A. (2005). The persistence of flexible organizational routines: The role of agency and organizational context, Organization Science, 16(6), 618-636. http://dx.doi.org/10.1287/orsc.1050.0150

Kenrick, D. T., Neuberg, S. L., \& Cialdini, R. B. (2005). Social psychology: Unraveling the mystery (3rd ed.). Auckland, New Zealand: Pearson Education.

Klepper, S. (1997). Industry Life Cycles. Industrial and Corporate Change, 6(1), 145-182. http://dx.doi.org/10.1093/icc/6.1.145

Levin, A. Y., \& Volberda, H. W. (1999). Prolegomena on Coevolotion: a framework for research on strategy and new organizational form, Organization Science, 10(5), 519-534.

Lovas, B., \& Ghoshal, S. (2000). Strategy as Guided evolution, Strategic Management Journal, 21(9), 875-896. http://dx.doi.org/10.1002/1097-0266(200009)21:9<875::AID-SMJ126>3.0.CO;2-P

Makin, P., Cooper, C., \& Cox, C. (1997). The psychological contract in organizations. Schoonhoven: Academic Press.

Metcalfe, J. S. (2006). Evolutionary Economics and Creative Destruction. London: Routledge.

Murmann, J. P., Aldrich, H. E., Levinthal, D., \& Winter, S. G. (2003). Evolutionary Thought in Management and Organization Theory at the Beginning of the New Millennium. Journal of Management Inquiry, 12(1), 22-40. http://dx.doi.org/10.1177/1056492602250516

Nelson, R. R. (1995). Recent Evolutionary Theorizing About Economic Change. Journal of Economic Literature, 33(1), 48-90. http://dx.doi.org/10.2307/2728910

Nelson, R. R. (2009). Routines as technologies and as organizational capabilities. In: M. Becker \& N. Lazarick (Eds.), Organizational routines. Advancing empirical research. Cheltenham: Edward Elgar.

Nelson, R. R., \& Winter, S. G. (1982). An Evolutionary Theory of Economic Change. Cambridge: Belknap Press.

Nemancich, L. A., \& Keller, R. T. (2006). Leading through the exploration/exploitation paradox: How top executives define their firm's innovation trajectory. Annual Meetings of the Academy of Management. Atlanta.

Pentland, B. T., \& Feldman, M. S. (2005). Organizational routines as a unit of analysis. Industrial and Corporate Change, 14(5), 793-815. http://dx.doi.org/10.1093/icc/dth070

Pentland, B. T., Haerem, T., \& Hillison, D. W. (2009). Using workflow data to explore the structure on organizational routine (pp. 47-68). In M. Becker \& N. Lazarick (Eds.), Organizational routines. Advancing empirical research. Cheltenham: Edward Elgar.

Pervin, L. A. (1989). Personality: theory and research. New York: Wiley.

Pettigrew, A. M. (1979). On Studying Organizational Cultures. Administrative Science Quarterly, 24(4), 570-581. http://dx.doi.org/10.2307/2392363

Pettigrew, A. M. (1987). Context and action in the transformation of the firm. Journal of Management Studies, 24(6), 649-670. http://dx.doi.org/10.1111/j.1467-6486.1987.tb00467.x.

Robbins, S., \& Coulter, M. K. (2005). Management. Prentice Hall: Pearson Education.

Robbins, S. P. (2015). Organizational Behavior (16th ed.). Cloth: Prentice Hall.

Salvato, C. (2003). The role of micro-strategies in the engineering of form evolution. Journal of Management Studies, 40(1), 83-108. http://dx.doi.org/10.1111/1467-6486.t01-2-00005

Salvato, C. (2009). The contribution of event-sequence analysis to the study of organizational routines (pp. 68-102). In M. Becker \& N. Lazarick (Eds.), Organizational routines. Advancing empirical research. Cheltenham: Edward Elgar.

Santos, V., \& Garcia, T. (2007). The complexity of the organizational renewal decision: the management role. Leadership \& Organization Development Journal, 28(4), 336-355.

Schein, E. H. (1985). Organizational Culture and Leadership. A dynamic view. San Francisco: Jossey-Bass Pub.

Siggelkow, N. (2001). Change in the presence of fit: the rise, fall, and renaissance of Liz Claiborne. The Academy of 
Management Journal, 44(4), 838-854. http://dx.doi.org/10.2307/3069418

Sober, E., \& Wilson, D. (1998). Unto Others: The Coevolution and Psychology of unselfish behaviour. Cambridge: Harvard University Press.

Steinmann, H., \& Schreyögg, G. (2005). Management. Grundlagen der Unternehmensführung. Konzepte-Funktionen-Fallstudien. Gabler: Wiesbaden.

Teece, D. J. (2010). Business models, business strategy and innovation. Long Range Planning, 43(2-3), 172-194. http://dx.doi.org/10.1016/j.lrp.2009.07.003

Van de Ven, A. H. (1987). Review essay: four Requirements for Processual Analysis (p. 331). In A.M. Pettigrew (Ed.), The management of strategic change. Oxford: Blackwell.

Van der Aalst, Reuers, H. A., \& Song, M. (2005). Discovering social networks from event logs. Computer Supported Cooperative Work. The Journal of Collaborative Computing, 14(6), 549-593. http://dx.doi.org/10.1007/s10606-005-9005-9

Venkatraman, N. (1989). Strategic orientation of business enterprises: the construct, dimensionality, and measurement. Management Science, 35(8), 942-962. http://dx.doi.org/10.1287/mnsc.35.8.942

Volberda, H., \& Lewin, A. (2003). Co-evolutionary dynamics within and between forms: from evolution to co-evolution. Journal of Management Studies, 40(8), 2111-2136. http://dx.doi.org/10.1046/j.1467-6486.2003.t01-2-00413_2.x

Wirtz, B. W., Mathieu, A., \& Schilke, O. (2007). Strategy in High-Velocity Environments, Long Range Planning, 40(3), 295-313. http://dx.doi.org/10.1016/j.lrp.2007.06.002

Zajonc, R. B. (1965). Social facilitation, Science, 149.

Zimbardo, P. G. (2005). Psychology and Life. Allyn \& Bacon Publishing.

Zollo, M., \& Winter, S. G. (2002). Deliberate Learning and the Evolution of Dynamic Capabilities. Organization Science, 13(3), 339-351. http://dx.doi.org/10.1287/orsc.13.3.339.2780 